\title{
Roadmap to digitalisation of an emerging economy: A viewpoint
}

\author{
Manas Paul \\ Institute of Management Technology (IMT) Ghaziabad, India \\ Email: mpaul@imt.edu \\ Parijat Upadhyay \\ Institute of Management Technology (IMT) Nagpur, India \\ Email: parijat.upadhyay@gmail.com
}

\author{
Yogesh K Dwivedi (Corresponding Author) \\ Emerging Markets Research Centre (EMaRC), School of Management, Swansea University, \\ Swansea, Wales, UK \\ Email: ykdwivedi@gmail.com
}

\begin{abstract}
Purpose: This article posits a critical analysis of digitalisation initiatives of emerging economies with a focus on India. It suggests granular policy measures towards realising the dream of a competitive, empowered and knowledge-based society. To this extent, the article juxtaposes and compares policy measures undertaken by several governments to facilitate digitalisation in their country. The relevance of policy measures is critically analysed, highlighting the challenges for their implementation and adoption within the prevailing social and economic fabric of the country. At the same time, it attempts to benchmark against the best practice standards weighed in by the industry studies. The article also suggests a robust agenda for future research.
\end{abstract}

Methodology/Approach: This is a viewpoint study based on public data and documentary sources within India and publications of several countries and international agencies. Research projects of numerous multinational companies working in the area of digitalisation were accessed and analysed in the study.

Findings: The findings of this study have policy implications for governments in several emerging economies which have embarked on the path of digitalising their economy with the broader objectives of reaping enhanced benefits but have to deal with the challenges of inadequate resources to create a meaningful ecosystem to facilitate such a transition. 
Originality: The study highlights the implications of challenges of gaps of physical and socioeconomic infrastructure in driving digitalisation, highlighting granular policy measures for public managers and policymakers to address them.

Keywords: Digitalisation, digitisation, government policy.

Article Type: Viewpoint

\section{Introduction}

In this all-encompassing age of digitisation, digital innovation and capabilities would increasingly differentiate between the winners and the losers. Emerging economies, including India, are aspiring to play a meaningful role in this process. The 'digital dream' for India is to transform into a digitally connected society that enables seamless access to and use of information resources that help create a competitive, innovative and knowledge-based society. The challenge before such economies is to define a successive path to realise the dream. Governments have formulated several policies related to the development of information technology (IT) and IT infrastructure (like that of The National Digital Communications Policy (NDCP-2018) of the Government of India. Such policy formulation is a good starting point in the right direction in making digitisation a national agenda by stipulating broad objectives and strategies. However, it would need the specificities of a seamless timeline and synchronisation across specific targets with associated accountabilities (Melin and Wihlborg, 2018). At the same time, the fructification of the 'dream' also rests on two critical pillars - (i) the requisite infrastructure and paraphernalia (Dahiya and Mathew, 2018) facilitating access to technology and (ii) its adoption by the population at large (Dwivedi and Williams, 2008; Dwivedi et al., 2007ab, 2012, 2016; Kapoor et al., 2014; Rana et al., 2013a,b; Khanra and Joseph, 2019; Slade et al., 2014; Weerakkody et al., 2009; 2007). Despite recent improvements and rising aspirations, emerging economies like that of India continue to lag in information and communication technology (ICT) infrastructure compared with our global peers. That apart, visualising the 'digital dream' from the perspective of technology adoption 
brings to fore the inherent differences in its relevance across different sections of society regarding understanding and ability to adapt. That poses a mounting challenge towards its fructification. In the absence of proper adoption, despite the provision of necessary infrastructure, there is the danger

of creating a digitally divided economy. This article posits a critical analysis of the development thus far with a focus on India and suggests granular policy measures towards realising this dream of transitioning to a competitive, empowered and knowledge-based society.

Section 2 in the article sets the theoretical background. Section 3 then provides data analysis and discussion. Section 4 deals with the discussion of the specifics of successful digitalisation strategy, and Section 5 provides the conclusion and road ahead.

\section{Theoretical background}

\subsection{The wave of digitalisation}

Digitisation, as it stands now, remains an unstoppable development with a significant bearing on human civilisation through the process of its social, cultural and technological evolution. It refers to business and economic processes driven by 'the changes associated with the application of digital technology in all aspects of human society' (Stolterman and Fors, 2004, p. 689). It has transformed the global value chain, giving rise to digital-platform-based activities such as the gig economy that is characterised by the short-term contract work (Graham et al., 2017). Besides, there have been instances of cloud work, socially responsible outsourcing or impact sourcing (Heeks and Arun, 2010; Nicholson et al., 2017), generating new opportunities in subsistence agriculture, responsible tourism, social intermediation (Kistruck et al., 2013) social entrepreneurship (Bhatt $e t$ al., 2017) and social business (UNCTAD, 2017).

The new-age digital companies like Amazon, Facebook and Google have grown to gigantic proportions in value and influence, in time seldom witnessed in corporate history. The likes of Google, Facebook and Amazon did not even exist 25 years back. However, today the five most valuable US tech companies account for around $17 \%$ of the S\&P 500. In contrast, companies that have otherwise been long-standing leaders in their respective domains find their traditional value proposition shaken up, under threat or decimated. Kodak, once the leader in production, design and marketing of photographic equipment, failed to keep up with digital revolution and filed for 
bankruptcy in 2012. Founded in 1960, the Tower Records conceptualised the retail music megastore. However, it failed to protect itself from the digital disruptions brought in by iTunes, Spotify and Pandora. Similarly, the international book and music retailer Borders fizzled out due to its inability to transition to the new environment of digital and online books. There are other examples of the application of digital technology in business innovation like Uber disturbing conventional taxi business (Pepic, 2018) and Airbnb disturbing traditional hotel business (O'Shaughnessy, 2019). Regarding its potential, digitalisation is capable of reshaping markets faster than perhaps any force in history, compelling businesses to reconsider their conventional sources of value creation.

\subsection{Digitisation: Differentiators and competitiveness}

Digital innovation and capabilities are increasingly differentiating the winners from the losers in society. In business, it is lowering entry barriers, disaggregating value chains and creating openings for fast-focused and fast-paced competitors. Carcary et al. (2016) talk about the centricity of digital technology to business operations and for organisations to effectively re-think and possibly re-invent their business models to maintain their competitive edge. While digitisation, ICT and technological innovation have their apparent overlaps, the existing literature linking digitisation and business/economic performance remains biased towards technological innovations (e.g. mobile technologies, analytics solutions), though the subject is meant to have a wider scope.

Although digitisation and digital transformation remain popular among practitioners, the term somehow appears to be less prevalent in the scholarly literature (Reis et al., 2018), and hence falls short of covering the broader scope of its actual potential in academic research. Nonetheless, Katz and Koutroumpis (2013) measure digitisation by six elements - (i) affordability, (ii) infrastructure reliability, (iii) network access, (iv) capacity, (v), usage and (vi) human capital, which gets captured by 23 indicators. In their study, a 10-point rise in their digitisation index induces an annual increase in GDP in the range of $0.4 \%-0.5 \%$ across advanced, transitional and emerging digitised countries. 
'Digitalisation' as a concept, however, find various mention in academic literature. There are differences between the words digitisation and digitalisation. In its strictest form, the latter extends the concept of digitisation far beyond its scope of automation of the existing manual and paperbased resources from an analogue to a digital format. Whereas digitalisation refers to the transformation of business operations/functions/models/processes and activities by leveraging digital technologies along with the broader use of digitised data, turning it into actionable knowledge, with a specific benefit in mind. The extant professional literature (MIT - Capgemini, 2013; IBM Institute for Business Value, 2012) emphasises four critical aspects of digital transformation - (i) digital capabilities, (ii) business models, (iii) operational process and (iv) user (internal and external IT consumer) experience. The IBM report summarises the overlaps of ICT, digitisation and technological evolution and their impact on productivity and competitiveness and their influence on three broad parameters - (i) business performance, (ii) agility and (iii) organisation change and performance.

\subsection{Digitalisation: Initiating social innovation}

Digitalisation triggers digital social innovation by providing a platform to business, nongovernment organisations, social entrepreneurs and government agencies to generate positive social impact by leveraging digital technologies. Studies by Reinecke and Ansari (2016) discuss about the use of technology to solve social problems. Digital technologies can co-create knowledge and solutions through collaboration among various entities that get attracted to this ecosystem to address a wide range of social needs of the disadvantaged, socially excluded and marginalised groups. Moreover, this can happen at a scale that was unthinkable before the rise of Internet-based technologies. Despite the rising potential for using emerging ICT innovations to address social issues, its potential remains largely unfulfilled in emerging economies. These developments represent an excellent opportunity for such economies involving both the public and private sectors to create social value through digital innovation or digital transformation.

\subsection{Potential risks and the need for effective regulation}

Although businesses eye opportunities in the process of digitalisation, there are challenges and risks galore those need to get addressed at the societal level. Issues such as information and cybersecurity risks, and intellectual property thefts (Deloitte, 2018) are some of the dangers faced 
by citizens daily. It is worth pointing out that a sizeable section of the Indian population may be lacking the necessary knowledge to participate in a digitally empowered society. Weerakkody et al. (2013) pointed out the lack of exposure and limited infrastructure, forcing an element of deprivation from the benefits of technological intervention in government initiatives. The United Nations E-Governance Survey 2018 mentions about the risk of the digital divide in the world, owing to insufficient access in low-income countries, because of lack of devices, bandwidth, speed or necessary skills or because of high access cost.

Moreover, with the complex role that technology plays today, it is not always neutral in its impact either. If a digital world is capable of fetching the benefits of bringing people together globally, the footprints of digital shoppers are collected and sold to advertisers to facilitate targeted advertising. In essence, users' data thus can get unknowingly sold as digital products to the highest bidder. There is a risk even in global connection leading to overwhelming internationalisation and social media impact; crowding out local content, culture and entrepreneurship. Herein lies the need for judicious use of technology, which can happen only at the back of effective regulation, undoubtedly a challenging balancing task.

\subsection{Constituents for realising the 'digital dream'}

Any discussion of 'digital dream' surrounds the theme of a digitally connected society that facilitates seamless access to and transfer of knowledge in creating a more empowered and innovative knowledge-based society (Digital India Programme).

The realisation of the 'digital dream' depends on two critical components - the requisite infrastructure (Dahiya and Mathew, 2018) and access to technology and its adoption by the population (Khanra and and Joseph, 2019) at large. Reddick (2009) emphasises the identification of adoption criterion of citizens for proper institutionalisation of eGov and interoperable public service system in the country.

As per a United Nations Department of Economic and Social Affairs (UNDESA) report, which tracks e-participation of citizens and business in a country, India scores quite poorly regarding telecommunication and infrastructural support and as a result gets a rank of 96 (among 193 countries). Thus, for emerging economies having ICT characteristics like India, there is the 
necessity for adequate thrust to both development of the required infrastructure at the earliest and at the same time ensure more participation across all sections of the society.

Table I. E-Government Development Index (EGDI) Rank Across years (Note: India and most of her global peers have lots of

\begin{tabular}{|l|r|r|r|}
\hline Countries & 2014 & 2016 & 2018 \\
\hline India & 118 & 107 & 96 \\
\hline China & 70 & 63 & 65 \\
\hline Pakistan & 158 & 159 & 148 \\
\hline Sri Lanka & 74 & 79 & 94 \\
\hline Indonesia & 106 & 116 & 107 \\
\hline Republic of Korea & 1 & 3 & 3 \\
\hline
\end{tabular}

Source: Compiled by authors based on UNDESA Reports of 2014, 2016 and 2018

Table I shows South Korea to be a leader in E-government development despite a little slide in its ranking over the years. Hence as a country, it provides a good reference point for others to pursue. Among the remaining countries, though all have shown improvements in ranking over the years, Sri Lanka stands out as the only one that witnessed a persistent deterioration in its ranking.

Table II. Telecommunication Infrastructure Index (TII) Across Years (Note: Telecommunication infrastructure remains a veritable drag for India and most of her peers)

\begin{tabular}{|l|r|r|r|}
\hline Countries & 2014 & 2016 & 2018 \\
\hline India & 0.1372 & 0.143 & 0.2009 \\
\hline China & 0.3554 & 0.3673 & 0.4735 \\
\hline Pakistan & 0.1174 & 0.1299 & 0.1529 \\
\hline Sri Lanka & 0.2341 & 0.2445 & 0.3136 \\
\hline Indonesia & 0.3054 & 0.3016 & 0.3222 \\
\hline Republic of Korea & 0.935 & 0.853 & 0.8496 \\
\hline
\end{tabular}

Source: Compiled by authors based on UNDESA Reports of 2014, 2016 and 2018

The constant deterioration in EGDI rank for Sri Lanka witnessed earlier gets reflected in the continuous decline in its TII over the years are represented in Table II. The rest of the countries though have shown improvements, they continue to lag way behind South Korea.

Table III. E-Participation Index Rank Across Years (Note: India fares relatively better than her global peers in E-participation

\begin{tabular}{|l|r|r|r|}
\hline Countries & 2014 & 2016 & 2018 \\
\hline India & 40 & 27 & 15 \\
\hline China & 33 & 22 & 29 \\
\hline
\end{tabular}




\begin{tabular}{|l|r|r|r|} 
Pakistan & 97 & 114 & 115 \\
\hline Sri Lanka & 33 & 50 & 85 \\
\hline Indonesia & 110 & 114 & 92 \\
\hline Republic of Korea & 1 & 4 & 1 \\
\hline
\end{tabular}

Source: Compiled by authors based on UNDESA Reports of 2014, 2016 and 2018

In emerging economies like India, the structural aspects of differentiated sections of the society (regarding education, understanding, income and ability to adopt new practices) can pose a significant challenge to digitalisation and the prospects of living the digital dream. In the absence of proper adoption, despite the provision of necessary infrastructure, there is the danger of creating a digitally divided country. Although it might still culminate into digital dream for some, it would risk the forcing out of many or most of the weaker sections of the Indian society into the realm of digital nightmare. Hence, the need to assess and facilitate 'e-readiness' to adapt to the wave of digitalisation remains equally important.

\subsection{Economic and social impact of digitalisation}

No analysis is complete without a discussion of the social and economic impact of digitalisation. Given that the full-fledged global digitalisation remains uneven across countries and continents, the understanding of such impact is partly still at an expectational level. Hence, it makes more sense to understand such expectations. Catherine et al. (2018) provide some crucial insights from its survey of large companies on the expected impact of digitisation on different macroeconomic aggregates.

The results showed an overwhelmingly positive impact of digitalisation on sales, pricing and productivity. In terms of specificity, the productivity effect is more pronounced in the services sector and more so in business-to-business segments. On pricing, the adoption of digital technologies enables producers of goods to increase their prices. Whereas responses from service providers (especially retailers) showed that adoption of digital technologies by others could put downward pressure on their prices. On sales, adoption of digital technologies facilitated expectations of assessing consumer needs through better access to consumer data and easier market 
access. Moreover, there were expectations on digital technology helping in sourcing optimisation and reducing frictions and wastage across the value chain.

However, the impact on employment is not straightforward. This survey points to digitalisation increasing the ratio of high-skilled to low-skilled workers. At the least, it meant the replacement of low-skilled jobs by machines and automation. In this context, a World Economic Forum report (2020) points to the gaining momentum of the question - whether technology creates or destroys jobs?

Although the actual answer is not known yet, it would depend on a host of factors such as the economic impact of future innovations, the way humans start interacting with machines and algorithms, the type of skills needed and learnt and how these factors end up impacting the labour markets.

While the World Economic Forum study points to the upside potential of digitisation, creating nearly 6 million jobs by 2025 in electricity and logistics industry alone, there are concerns of job losses as well in specific sectors.

The report mentions of jobs that would lose the race against machine, like clerks, and administrative staff. Broadly, all these point mostly to repetitive jobs that could be easily automated. However, at the same time, it talks about the increased role for creative jobs which machine can seldom perform. All these have significant ramifications both for organisations and governments. As the pace of digital transformation is playing out rather quickly than previous technological innovations like the industrial revolution, the organisations need to have a nimble strategy to reskill workers at a faster pace. Governments needs to be mindful of and be prepared to deal with potential issues such as inequality, wage deflation and even social unrest if they do not succeed in preparing the workforce for the digital future.

\section{Data analysis and discussion}

The analysis in the article is drawn upon information from secondary data and documentary sources in India, other emerging markets and international agencies. Research projects of several multinational companies working in the area of digitalisation were accessed as well to incorporate 
their learnings into the study. This article tries to assimilate industry practice and academic literature that could pave the way for future research.

\subsection{Government achievements}

In this respect, this study analyses the Government of India's National Digital Communication Policy (NDCP) of 2018. The NDCP-2018 supersedes the National Telecom Policy 2012 (NTP 2012) for the country. The three-pronged approach of this policy, Connect-Propel-Secure, does encompass all aspects of digital communications.

However, the stated vision in the policy needs the support of meticulous implementation plans and adherence to timelines. Otherwise, it runs the risk of repeating the experience of National Telecom Policy 2012, whose objectives of 70\% rural teledensity by 2017 and connectivity of villages remain unfulfilled even today. The rural teledensity continues to lag below 60\%, and till 1 March 2020, only 138,066 gram panchayats have been made service ready for providing broadband connectivity against the objective to connect all the 250,000 villages by 2016 .

Despite recent strides, India continues to struggle on other parameters of digitalisation in terms of global comparison. According to a 2018 report of the Pew Research Centre, India lags in Internet connection (measured by Internet use or smartphone ownership). Only $25 \%$ of the adults use the Internet or own a smartphone vis-a-vis global median of $75 \%$. Likewise, only $20 \%$ of adults use social media against the global median of 53\%. Such figures are in line with some of the poorest and less developed countries in sub-Saharan Africa (Pew Research Centre, 2018). The report also points to a clear positive linkage between usage/adoption of digitalisation to education and income, the levels of which remain a structural constraint for India and many emerging nations (Pew Research Centre, 2018).

The speed of Internet connection remains another area of concern. According to Ookla Speed Test Global Index for February 2020, with the country's average mobile data download speed of 11.83 Mbps, India ranks 128th among 141 countries and remains well below the global average of 31.61 Mbps.

Regarding the average fixed broadband speed, India ranks relatively better at 69 among 176 countries with an average rate of 39.65 . Mbps, but still way below the global average at 75.41 
Mbps. Not only that, there remains a wide regional variation as well with the southern state Karnataka faring lot better compared with the North-Eastern states.

Amidst these constraints, the government, TRAI and the telecoms have failed in ensuring necessary mobile call quality. The menace of call drop with no accountability continues. Along with that, there are issues of high price of spectrum auctions amidst a highly competitive environment amidst stiff competition from Reliance Jio, pushing telcos into bankruptcy. In this background with the telcos deep down in debt (more than $\$ 9.45$ billion $^{1}$ ), the NDCP-2018 goal of $\$ 100$ billion investment over 4 years appears to be an ambitious proposition.

Moreover, as per NDCP-2018, of the approximately 1.5 million kilometres of OFC network that India has, less than one-fourth of the towers are fibre-connected. The policy highlights the relevance of next-generation networks like $5 \mathrm{G}$ and groundbreaking network access technologies like satellite communications to facilitate the expansion of mobile and broadband connectivity across the country. In this respect, it would be critical to focus on the initiatives towards developing the digital communication infrastructure related to fibre deployment and Right of Way clearances, for both overground and underground infrastructure, as that will form the foundation of nextgeneration technologies.

NDCP-2018 identifies the need to strengthen the sector's institutional mechanism and legislative framework, enabling citizens to derive the full potential of its digital communications sector. Post this broad agenda, the need of the hour is granular details of particular amendments or sequential legislations that are being planned at this stage to achieve both the intermediate objectives and the final goal. Teemu et al. (2019) emphasised on the issue of project governance in context to the government initiatives for digitalisation.

\subsection{Digital literacy scenario}

Digital literacy, especially in India, is another critical area that needs immediate focus as one of the essential planks for successful digitalisation. From March 2014, India has embarked upon several digital literacy missions with its latest avatar in the form of Pradhan Mantri Gramin Digital Saksharta Abhiyan (PMGDISHA). There are controversies associated with the implementations

The general estimates of existing debts of telcos range in excess of INR 07 lakh crore. That is converted into US dollar at the USDINR rate of 74.04 . 
and impact of these missions. Not only did the original deadline for National Digital Literacy Mission got extended from 18 to 27 months but also it got scrapped in June 2016. While this programme was running, the government introduced Digital Saksharta Mission (Disha) in 2015 with a target of training 5.25 million citizens over 4 years at the cost of INR 3.48 billion. As per government claims, this target was met in half that time, although some of the independent impact assessment studies pointed out several gaps. There were concerns that one of the primary eligibility criteria for this programme was one member from a household where nobody between 14 and 60 years of age is an IT literate. There are concerns over adherence to this criterion. There are reports that state $74.3 \%$ of the people trained were from families with one IT-literate member and one in four came from families where two or more were digitally literate. Furthermore, there are apprehensions of inadequate representation from the scheduled caste and scheduled tribe community. Moreover, in its recent avatar, the PMGDISHA launched in the first half of 2017 had the target of training 60 million people by March 2019. Interestingly, as of 27 March 2020, there were only around 30 million people (less than $50 \%$ of the targeted population) who got trained amidst several noises about inefficiencies surrounding its implementation (Rachna, 2019).

\subsection{Addressing the gaps}

The world leaders adopted an ambitious roadmap guiding sustainable development programme for all nations at the September 2015 United Nations Summit in New York, titled 'Transforming our world: the 2030 Agenda for Sustainable Development'. It defined 17 sustainable development goals (SDGs) and 169 targets to stimulate actions for people, planet, prosperity, peace and partnerships. These goals and targets are pertinent in fortifying the achievement of SDGs as a whole. Herein the deployment of e-government in support of good governance has been envisaged as essential for building inclusive accountable and effective institutions at all levels.

To develop knowledge societies, accelerate human progress and bridge the digital divide to increase competitiveness, the UN E-Government Survey 2018 highlights the need for taking a focused approach to addressing the following issues:

i) National policy alignment (business with Digital India Policy)

ii) Public trust (measures to instil more participation of citizens) 
iii) Policy integration and coherence in e-government approach

iv) Societal engagement and partnerships (to improve e-readiness of the society at large)

v) Effective institutions to encourage the adoption of innovative technologies

The United Nation's SDGs have highlighted social issues and problems that require innovative and socially embedded solutions leveraging digital technology. Addressing SDGs is expected to help create competition within corporations to enhance their performance in these environments.

Fulfilment of SDGs would not only require the leveraging of the existing and widely deployed technologies but is expected to explore creative services and superior reach of technological solutions. The existing literature portends to the extended role that ICT is poised to play in today's low-income countries (Faik and Walsham, 2013). The mobile phone diffusion phenomenon presented in Meso et al. (2005) indicates the possibilities for developing countries to potentially 'leapfrog' through their use of mobile-platform-based ICTs and applications to achieve digital transformation. Such phenomenon indicates the potential for these countries to close the technological gap with developed countries at a much faster rate than previously anticipated (Datta, 2011; Tim et al., 2017), laying down exciting possibilities to leverage.

ICTs are increasingly enabling and driving the transformation of critical public services such as healthcare, education, energy, agriculture and environmental monitoring and protection in both the developed and developing countries (Chandwani and Dwivedi, 2015; Riaz and Qureshi, 2017; Stahl et al., 2012). Digital platforms and crowdsourcing have led to innovative social solutions and services in the third sector (or popularly known as charitable sector) such as more fluid, decentred and dynamic ways of achieving social inclusion. In this perspective, attempts to identify the existing gaps between India and her digitally advanced counterparts and peer groups as well as the analysis of how they have progressed in the last couple of years could provide the requisite information to flesh out the necessary path towards meaningful digitalisation.

In this context, it is worth mentioning that the government alone will find it difficult to effect a societal transformation based on the digital platform, and so an inclusive approach should be the way forward. Partnerships of diverse nature are required to reach out to all the citizens in these countries. An e-ready and all-inclusive foundation (bottom of the pyramid) will undoubtedly fuel the competitiveness of these countries in the years to come. 


\section{Arriving at the specifics of successful digitalisation strategy}

Earlier in the text, we have highlighted that NDCP-2018 has done a good job in highlighting the targets, but a lot more is desired in terms of specific non-conflicting goals and their proper sequencing towards attaining them. The major challenge for administering such a policy across India lies in the diversity of the stakeholders, their perspectives and ambitions. Considering the complexities involved, there is the need for a stringent action plan to mitigate avoidable risks which might otherwise result either in substantial losses during the tenure of the project or lead to actual outcome undershooting expectations and heightening the risks of project failure. Hence, what is required is an in-depth analysis of digitalisation from planning to the implementation phase. Sivamalai (2013), in a related article, identifies divergent interests and differences in stakeholders' expectations as one of the main reasons for the failure of e-government projects. In their study of realising digital identity in government while analysing design and implementation of Aadhar (a initiative undertaken by the Government of India to provide an unique number to every citizen of the country), Mir et al. (2019) highlight the importance of prioritisation of goals and proper sequencing of design, development and implementations with a focus on stakeholders' aspirations in the field of ICT development.

At the same time, given the diversity that India has in terms of culture, varied demographics, religious and political beliefs, income and education level, it is likely to impact ICT adoption rates across the 29 states and seven union territories of the country. With this background, the requirement could be to move away from a one-for-all approach for digitalisation and allow for multilevel differences in intervention as might be required by the society.

An encouraging finding from a study (Upadhyay and Roy, 2017) undertaken in the Indian context to understand the readiness of citizens to embrace digitalisation is the user proactive participation and acceptance of technology in the society. Today, the user is better prepared for the technological leap. Even the low-income respondent seemed to enjoy a certain degree of comfort to use technology. No more a less educated or a person from the deprived section of society suffers from an inferiority complex when it comes to the handling of technological gadgets. The major limitation is their spending ability on the types and sophistication of the technical gadgets. However, whatever they have access to, they consider themselves quite competent in using those 
gadgets. Penetration of cell phones, televisions and other consumer electronic items in the rural areas is a testimony to this.

With computing shifting mostly to handheld devices through mobile handsets, it provides an enormous opportunity to the government as far as e-governance is concerned. The government may find it increasingly convenient to connect to an ordinary man, and hence its schemes can reach them more effectively. Citizens can now voice their opinions more than before and is indeed a very encouraging trend in a developing country like India where several social schemes can be fine-tuned with the participation of the stakeholders to make it more inclusive and meaningful.

The extant literature talks about using the Social Construction of Technology (SCOT) framework to understand the differences in stakeholders' perception of digitalisation and how analysis of design decisions before implementations could address such issues. Moreover, Mir et al. (2020), show prospects for extending it to evaluate the design and implementation decision during the tenure of the project to mitigate the risks of project failure.

For its overall success, it is pertinent to identify the overarching goals for digitalisation and map its dependence on the various factors/criteria that need to be satisfied right from the planning phase. Given the level of complexities involved, there might be the necessity to make judgements about smaller components of the entire decision-making process and reassemble the pieces to present the overall picture that ensures that prospects of more than one conflicting criterion do not compromise with project viability. The rich body of literature (Mardani et al. 2015) of multiple criteria decisionmaking (MCDM) tool can be explored to address this.

From the theoretical perspectives, the study could throw opportunities to apply critical success factors (CSF) theory to identify diagnostic success factors and their significance. Moreover, exploration of relevant facets of Deferred Action Theory (DAT), Design theory, systems theory and stakeholder theory might be necessary to ensure proper sequencing and prioritisation in the identification of design and execution choices.

\section{Conclusion and the road ahead}

As emerging countries like India remains better prepared to take the technological leap, the government needs to create a conducive environment in the country not only by setting up ICT 
infrastructure but also by encouraging private participation to penetrate further in the rural hinterlands. Tribunals need to be formed for the grievance redressal mechanism under the watchful eyes of appropriate regulatory authority to curb any unfair practice by any stakeholder. The government initiative needs to be geared towards taking the ICT revolution far and wide across the length and breadth of the country to both empower the public and ensure delivery of government policies.

Although NDCP-2018 has provided a broad mandate in the right direction, there are pressing requirements for specific policies encouraging the shift into a digitally empowered competitive society. However, one of the most critical requirements among them is the development of an ecosystem to facilitate inclusive digitalisation.

\subsection{Setting the future research agenda and road ahead}

Developing markets in the early stages of digitalisation generally focuses on boosting demand for essential telecommunications services such as fixed, mobile and broadband access across both the public and private sectors. There has been some progress here, even if more needs to be done. Nonetheless, as the markets mature, the government's focus needs to shift more towards facilitating the adoption of digitalisation.

Creating demand for digitalisation requires a high level of ICT literacy and skilled human capital. Policymakers, therefore, need to ensure two primary requirements: (i) investments in digitalisation through training programmes and education incentives and (ii) promoting high-speed broadband services and ensuring that these networks are widely available and affordable. These are some of the primary requirements to realise the digital dream in a way that it is accessible to every section of society in the shift to a more empowered and competitive society.

That would require the simultaneous operation of a multipronged strategy:

1. Ensure the availability of digital devices to perform some of the primary activities at affordable prices and access to power and meaningful network with full accountability of the service provider. The private sector can be roped in for this with incentivisation linked to the performance of such devices. Events like 'Digital Fairs' (it can be localised in terms of local uniqueness like for India it could be termed as 'Digital 
Melas') could be thought of to encourage local entrepreneurship to interact and collaborate with established players and to get a pulse of the specific needs of the prospective customer base.

2. Extensive training of people across age group, income and social class and literacy levels to ensure a certain minimum level of digital literacy across the country within a specific time frame. Such training is likely to need more customisations for the middleaged, old-aged, and a less literate populace. Herein, the role of trainers in the name of 'Digital Buddies' (it can be localised in terms of local uniqueness like for India it could be termed as 'Digital Sevaks') could be thought of to reach out to people at the comfort of their homes, facilitating learning at a time deemed more convenient to them. Incentives might be necessary to induce people into such training programmes until they get into the habit of doing so.

3. Provision of certain government services such as tax payments, driving license renewal and direct benefit transfers could be made compulsory through digital platform to facilitate the application of initial learning.

4. Extensive arrangements should go hand in hand for a programme of 'Digital Guides' (it can be localised in terms of local uniqueness like for India it could be termed as 'Digital Bandhu') along the lines of correspondent bankers whose role would be to sort out issues faced by people in their transition towards a digitally empowered society. They are likely to be skilled young ICT experts, acting as digital interpreters to improve technical capacity-building among citizens and rural businesses and sort out snags in their transitioning process at the comfort of their homes.

5. People should be given the necessary administrative assurance of their data security for the adoption of digitalisation at the country level. The 'Digital Buddies' and 'Digital Guides' should be able to advise people on dos and don'ts to ensure adequate safety of their digital interactions and transactions.

6. To encourage private participation in the digitalisation drive, corporate spending on digitalisation infrastructure or training facilities should get explicitly added to the list of activities permitted under Corporate Social Responsibilities like for India in schedule VII of Companies Act 2013. 
7. Given that a large part of emerging economies like India still resides in the villages, national-level policymakers need to consider the rural dimension more in the development of digitalisation projects/initiatives and regulations. Moreover, there should be thrust upon building local capabilities, in creating content and applications.

8. There needs to be close collaboration between private and public sectors through industry bodies, and government and industry policy consultations for investments, including incentives for private sectors in less attractive segments to make them investment-worthy.

9. Rural digitalisation regulations/projects/initiatives should be decentralised to local public authorities that have a better understanding of the specific rural conditions.

Steps like NDCP-2018 is a good step in the right direction in making digitalisation a national agenda by stipulating broad objectives, strategies and targets. However, what is most needed is the seamless synchronisation of timelines across specific targets with associated accountabilities. At the same time, there has to be a national will to ensure that such goals and priorities do not get waylaid by other dogmatic compulsions of democratic politics.

\section{References}

Bhatt, B., Qureshi, I. and Riaz, S. (2017), "Social entrepreneurship in non-munificent institutional environments and implications for institutional work: Insights from China", Journal of Business Ethics, doi.org/10.1007/s10551-017-3451-4.

Carcary, M., Doherty, E. and Conway, G. (2016), “A dynamic capability approach to digital transformation - A focus on key foundational themes", 10th European Conference on Information Systems Management, Academic Conferences and publishing limited, pp. 20-28.

Catherine, E., et al. (2018), "Digitalisation and its impact on the economy: Insights from a survey of large companies", ECB Economic Bulletin, Issue 7/2018, available at: https://www.ecb.europa.eu/pub/economicbulletin/focus/2018/html/ecb.ebbox201807_04.en. $\underline{\mathrm{html}}$

Chandwani, R.K. and Dwivedi, Y.K. (2015), “Telemedicine in India: Current state, challenges and opportunities", Transforming Government: People, Process and Policy, Vol. 9 No. 4, p. 393.

Dahiya, D. and Mathew, S.K. (2018), "IT infrastructure capability and e-government system performance: An empirical study", Transforming Government: People, Process and Policy, Vol. 12 No. 1, pp. 16-38.

Datta, P. (2011), "A preliminary study of ecommerce adoption in developing countries", Information Systems Journal, Vol. 21 No. 1, pp. 3-32.

Delloite (2018), “Managing risk in digital transformation”, Risk Advisory, January 2018. 
Dwivedi, Y., Khan, N. and Papazafeiropoulou, A. (2006), "Consumer adoption and usage of broadband in Bangladesh", AMCIS 2006 Proceedings, 426, doi: http://aisel.aisnet.org/amcis2006/426

Dwivedi, Y.K., Khoumbati, K., Williams, M.D. and Lal, B. (2007a), Factors affecting consumers' behavioural intention to adopt broadband in Pakistan, Transforming Government: People, Process and Policy, Vol. 1 No. 3, pp. 285.

Dwivedi, Y. K., Khan, N., \& Papazafeiropoulou, A. (2007b). Consumer adoption and usage of broadband in Bangladesh. Electronic Government, an International Journal, 4(3), 299-313

Dwivedi, Y.K., Sahu, G.P., Rana, N.P., Singh, M. and Chandwani, R.K. (2016), "Common Services Centres (CSCs) as an approach to bridge the digital divide", Transforming Government: People, Process and Policy, Vol. 10 No. 4, pp. 511-525.

Dwivedi, Y.K., Wade, M.R. and Schneberger, S.L. (Eds) (2011), Information Systems Theory: Explaining and Predicting Our Digital Society, Vol. 1, Springer, Heidelberg.

Dwivedi, Y.K., Weerakkody, V. and Janssen, M. (2012), "Moving towards maturity: challenges to successful e-government implementation and diffusion", ACM SIGMIS Database: the DATABASE for Advances in Information Systems, Vol. 42 No. 4, pp. 11-22.

Dwivedi, Y.K. and Williams, M.D. (2008), "Demographic influence on UK citizens' e-government adoption", Electronic Government, an International Journal, Vol. 5 No. 3, pp. 261-274.

Faik, I. and Walsham, G. (2013), "Modernisation through ICTs: Towards a network ontology of technological change", Information Systems Journal, Vol. 23 No. 4, pp. 351-370.

Graham, M., Hjorth, I. and Lehdonvirta, V. (2017), "Digital labour and development: Impacts of global digital labour platforms and the gig economy on worker livelihoods", Transfer: European Review of Labour and Research, Vol. 23 No. 2, pp. 135-162.

IBM Institute for Business Value (2012), CMOs and CIOs Acquaintances or allies? available at: https://www.ibm.com/smarterplanet/global/files/se_sv_se_intelligence_CMOs_and_CIOs. pdf

Kapoor, K.K., Dwivedi, Y.K. and Williams, M.D. (2014), "Innovation adoption attributes: A review and synthesis of research findings", European Journal of Innovation Management, Vol. 17 No. 3, pp. 327.

Katz, R. and Koutroumpis, P (2013), "Measuring digitisation: A growth and welfare multiplier", Technovation, Vol. 33 No. 10-11, pp. 314-319.

Khanra, S. and Joseph, R.P. (2018), "Adoption of e-Governance", Transforming Government: People, Process and Policy, Vol. 13 No. 2, pp 122-142.

Kistruck, G.M., Beamish, P.W., Qureshi, I. and Sutter, C.J. (2013), "Social intermediation in baseof-the-pyramid markets", Journal of Management Studies, Vol. 50 No. 1, pp. 31-66.

Mardani, A., Jusoh, A., Nor, K., Khalifah, Z., Zakwan, N. and Valipour, A. (2015), "Multiple criteria decision-making techniques and their applications - A review of the literature from 2000 to 2014”, Economic Research-Ekonomska Istraživanja, Vol. 28 No. 1, pp. 516-571.

Melin, U. and Wihlborg, E. (2018), "Balanced and integrated e-government implementation Exploring the cross road of public policy making and information systems project 
management processes", Transforming Government: People, Process and Policy, Vol. 12 No.2, pp. 191-208.

Meso, P., Musa, P. and Mbarika, V. (2005), "Towards a model of consumer use of mobile information and communication technology in LDCs: The case of sub-Saharan Africa", Information Systems Journal, Vol. 15 No. 2, pp. 119-146.

MIT - Capgemini (2013). Digital transformation: A roadmap for billion-dollar organisations, available at: www.capgemini.com/resourcefileaccess/resource/pdf/Digital_Transformation_A_Road-Map_for_BillionDollar_Organizations.pdf

Mir, U.B., Kar, A.K., Dwivedi, Y.K., Gupta, M.P. and Sharma, R.S. (2020), Realising digital identity in government: Prioritising design and implementation objectives for Aadhaar in India”, Government Information Quarterly, Vol. 37 No. 2, pp. 101442, doi.org/10.1016/j.giq.2019.101442.

Nicholson, B., Babin, R. and Lacity, M.C. (2017), Socially Responsible Outsourcing: Global Sourcing with Social Impact. Springer.

O'Shaughnessy, T. (2019), Airbnb's impact on the hotel industry: Insights from 1000 travellers who use both, available at: https://listwithclever.com/real-estate-blog/airbnb-vs-hotels-study/

Pepic, L. (2018), “The sharing economy: Uber and its effect on taxi companies", Acta Economica, Vol. XVI No. 28.

Pew Research Centre (19 June 2018), "Social media use continues to rise in developing countries, but plateaus across developed ones, digital divides remain, both within and across countries", available at: https://www.pewresearch.org/global/2018/06/19/social-media-use-continues-torise-in-developing-countries-but-plateaus-across-developed-ones/

Rana, N.P., Dwivedi, Y.K. and Williams, M.D. (2013a), "Evaluating alternative theoretical models for examining citizen centric adoption of e-government", Transforming Government: People, Process and Policy, Vol. 7 No. 1, pp. 27-49.

Rana, N.P., Dwivedi, Y.K. and Williams, M.D. (2013b), “Analysing challenges, barriers and CSF of egov adoption," Transforming Government: People, Process and Policy, Vol. 7 No. 2, pp. 177-198.

Reddick, C.G. (2009), "The adoption of centralised customer service systems: A survey of local governments”, Government Information Quarterly, Vol. 26 No. 1, pp. 219-226.

Reinecke, J. and Ansari, S. (2016), "Taming wicked problems: The role of framing in the construction of corporate social responsibility", Journal of Management Studies, Vol. 53 No. 3, pp. 299-329.

Reis, J., Amorim, M., Melao, N., Matos, P. (2018), "Digital transformation: A literature review and guidelines for future research", pp. 411-421, doi: 10.1007/978-3-319-77703-0_41.

Sivamalai, L. (2013), "Using the lens of 'social construction of technology' to understand the design and implementation of aadhaar (UID) project", IFIP Advances in Information and Communication Technology, Vol. 402, pp. 633-638. 
Slade, E.L., Williams, M.D. and Dwivedi, Y.K. (2014), "Devising a research model to examine adoption of mobile payments: An extension of UTAUT2", The Marketing Review, Vol. 14 No. 3, pp. 310-335.

Stahl, B.C., Doherty, N.F. and Shaw, M. (2012), "Information security policies in the UK healthcare sector: A critical evaluation," Information Systems Journal, Vol. 22 No. 1, pp. 7794.

Stolterman, E. and Fors, A.C. (2004), "Information technology and the good life", In: Information Systems Research: Relevant Theory and Informed Practice. Ed. Kaplan, B., Truex, D.P., Wastell, D., Wood-Harper, A.T., DeGross, J., Kluwer Academic Publishers, London.

Teemu, M.L., Kirsi A. and Jaakho K. (2019), "Project governance and portfolio management in government digitalisation", Transforming Government: People, Process and Policy, Vol. 13 No.2, pp. 159-196.

Tim, Y., Pan, S.L., Ractham, P. and Kaewkitipong, L. (2017), "Digitally enabled disaster response: The emergence of social media as boundary objects in a flooding disaster", Information Systems Journal, Vol. 27 No. 2, pp. 197-232.

UNCTAD, (2017), Information Economy Report 2017: Digitization, Trade and Development. Geneva, Switzerland: United Nations Conference on Trade and Development, available at: http://unctad.org/en/pages/PublicationWebflyer.aspx?publicationid=1872

United Nations E-Government Survey 2018, "Gearing E-Government to support transformation towards sustainable and resilient societies," available at: https://www.preventionweb.net/publications/view/59447

Upadhyay, P. and Roy, S.G. (2017), "Does e-readiness of citizens ensure better adoption of government's digital initiatives? A case based study", Journal of Enterprise Information Management, Vol. 30 No. 1, pp. 65-81.

Weerakkody, V., El-Haddadeh, R., Al-Sobhi, F., Shareef, M.A. and Dwivedi, Y.K. (2013), "Examining the influence of intermediaries in facilitating e-government adoption: An empirical investigation", International Journal of Information Management, Vol. 33, pp. 716725.

Weerakkody, V., Dwivedi, Y.K. and Kurunananda, A. (2009), "Implementing e-government in Sri Lanka: Lessons from the UK”, Information Technology for Development, Vol. 15 No. 3, pp. 171-192.

Weerakkody, V., Dwivedi, Y.K., Williams, M., Brooks, L., \& Mwange, A. (2007). E-government implementation in Zambia: contributing factors. AMCIS 2007 Proceedings, 323. Available at http://aisel.aisnet.org/amcis2007/323

World Economic Forum, "Understanding the impact of digitalisation on society," available at: https://reports.weforum.org/digital-transformation/understanding-the-impact-ofdigitalization-on-society/(accessed January 2020). 